\title{
Implementation of Prototyping Method on Website Development of Land use Mapping
}

\author{
Ginanjar Wiro Sasmito \\ Department of Informatics \\ Politeknik Harapan Bersama \\ Tegal, Indonesia
}

\author{
Arif Wirawan Muhammad \\ Department of Informatics \\ Politeknik Harapan Bersama \\ Tegal, Indonesia
}

\begin{abstract}
Increasing diversity of urban activity attracts many people to try their fate in urban areas so as to heighten the flow of urbanization. This resulted in a large demand for land supply to accommodate the increasing number of city dwellers. On the other hand, land is a very limited resource and cannot be created or renewed, so the problem that often arises is the proliferation of slum and squatter areas in urban areas. The solution to the problem is to produce a land use website. By using the prototyping method of land use website is generated in order to speed up the development of website and to really fit with the wishes and needs of the client.
\end{abstract}

Keywords:- land; prototyping; website; development; urban.

\section{INTRODUCTION}

The city is a container of mega-complex activities both between humans and humans as well as with the surrounding environment. The growth of the city is directly proportional to population growth, technological advances, and the increasing demands of practical and modern lifestyles. As a result, the city became unfriendly with its inhabitants, there were economic and social gaps in every corner of the city, congestion arises, pollution spread over the city, and so on. Urban planning is a spatial use design and arrangement that focuses on the physical form, economic function, and social impact of the urban environment and the location of the activities within it.

One of the branches of urban planning is land use planning. Land use is a recurring process based on a dialogue between all the mutually negotiating stakeholders and who want a decision for sustainable land use in rural areas to initiate and monitor its implementation [1]. The increasing diversity of urban activity attracts many people to try their fate in urban areas so as to heighten the flow of urbanization. This resulted in a large demand for land supply to accommodate the increasing number of city dwellers. On the other hand, land is a very limited resource and cannot be created or renewed, so the problem that often arises is the proliferation of slum and squatter areas in urban areas. The unpreparedness of the city government in anticipating the growth and development of the city, especially in terms of population is also a major factor in the emergence of urban and squat settlement areas. Bad land use mapping can cause several things, including:

- There is land used for facilities that are not as appropriate.

- Optimalization and efficiency of land use is not maximal.

- Existing public services become inhibited.

- Inhibits the productivity of existing resources
Land use mapping is usually developed using software, and one of the software development methods is prototyping. Prototyping method is one method of system life cycle based on working model concept. The goal is to develop the model into a final system. Prototyping can also be used by end users to describe and prove the terms that have not been considered, and that can be a key factor in commercial relationships between developers and clients [2]. Software development conducted in this research is to produce a website-based applications.

\section{RELATED RESEARCH}

The research that has been done by Sabale \& Dani 2012 , produces a Comparative Study of Prototype Model For Software Engineering With System Development Lifecycle. In the study it was submitted that many suggested models such as waterfalls, prototypes, rapid application development, Vshaped etc. in system development. All these different software development models have their respective advantages and disadvantages. Nevertheless, in the world of contemporary commercial software development, a mix of all these methodologies are combined. Thus, it is felt that some standard and structural procedures or methodologies are introduced in the industry so that the transition from manual to automatic system becomes easy by using system development methods [3]. Research [4] produced urban waste mapping using QuickBird NDVI and GIS Spatial Modeling for CoEfficient Runoff Detection. This study presents the integration of remote sensing and GIS to determine the runoff coefficient $(\mathrm{C})$ recommended by the American Society of Civil Engineers and the Water Pollution Control Federation in 1969. $\mathrm{C}$ is a runoff index used as an input parameter in the most commonly used procedure: The rationale method for the calculation of runoff rainwater in small calculations on the urban watershed for the design and analysis of storm drainage. The purpose of this study was to evaluate 8-bit and 16-bit Quick-Bird (QB) NDVI satellite images using unsupervised classification and ISODATA algorithm to map the resistant and open spaces used for the determination of $\mathrm{C}$ in GIS spatial [4].

In a study conducted by Gao et all, 2008 has produced an online GIS Service for mapping and sharing of disease information. In the study, cases of infectious disease mapping were conducted in New Brunswick (Canada) and Maine (USA) to evaluate the architecture used, using Web Map Service standards, the Styled Layer Descriptor and Web Map Context specifications. The results show the effectiveness of infectious disease surveillance systems and enable the visualization, analysis, and sharing of infectious disease 
information through interactive and / or animated maps. Collaborating on multiple partners through a distributed network and a service-based architecture enables open and interactive collaboration of data and users sharing [5].

Chang et all, 2009 also conducts research on Google Earth and GIS Technology Combination for Dengue Fever Mapping in Developing Countries as a Monitoring System. In his research visual image of dengue fever case location, larval breeding and potential larval development sites used by dengue control specifically to prioritize the intervened environment in order to exercise targeted control. The results of this study are particularly suited for limited control of resources as they utilize available technology that does not depend on Internet access for everyday use and can be easily applied in many developing countries at a very small cost [6].

In a study conducted by Mas, 2004 has produced a mapping of land use / cover in tropical coastal areas using satellite sensor data, GIS and artificial neural networks. The problem with this research is to classify remote sensing images to map land use / cover on different lands that can cause errors during classification. Therefore, land use mapping procedures / include the incorporation of spectral information from recent images and data on the spatial distribution of land use types obtained from cartography and supplementary data. Two fuzzy maps, which show the membership of each usage class generated from the supporting and spectral data, respectively, using the artificial neural network approach. The combined maps are both obtained using the fuzzy rule [7].

Another similar study was also conducted by Brewer, 2006 on Basic Mapping as a Principle in Visualizing Cancer Data Using Geographic Information Systems (GIS). Cancer researchers can take advantage of mapping geographic information systems (GIS) as one of many existing tools and can broaden the symbolization approach used to investigate and illustrate existing data. Single map is one of the many possible data representations, so by making some maps a complete mapping business. The type of symbols, color choices, and data classifications each affect the information revealed by the map and best suit the characteristics of the particular data. Related data can be checked simultaneously with a coordinated classification and can also be compared by using multivariate symbols built on the basic rules of symbol design [8].

\section{RESEARCH METHOD}

This research was developed with Computer Based System Engineering method based on the principles of System Development Life Cycle (System Development Life Cycle) with prototyping method. This prototyping method is also called Rapid Application Design because it simplifies and accelerates the system design [9]. Prototyping software (prototyping software) or life cycle using prototyping (life cycle using prototyping) is one method of system life cycle based on working model concept. The goal is to develop the model into a final system. This means that the system will be developed faster than traditional methods and the cost will be lower [10]. The prototyping process is an interactive and repetitive process that combines the steps of the traditional development cycle. The prototype was evaluated several times before the end user declared the prototype accepted [11]. The prototyping method scheme [12] can be seen in accordance with the following Fig. 1.

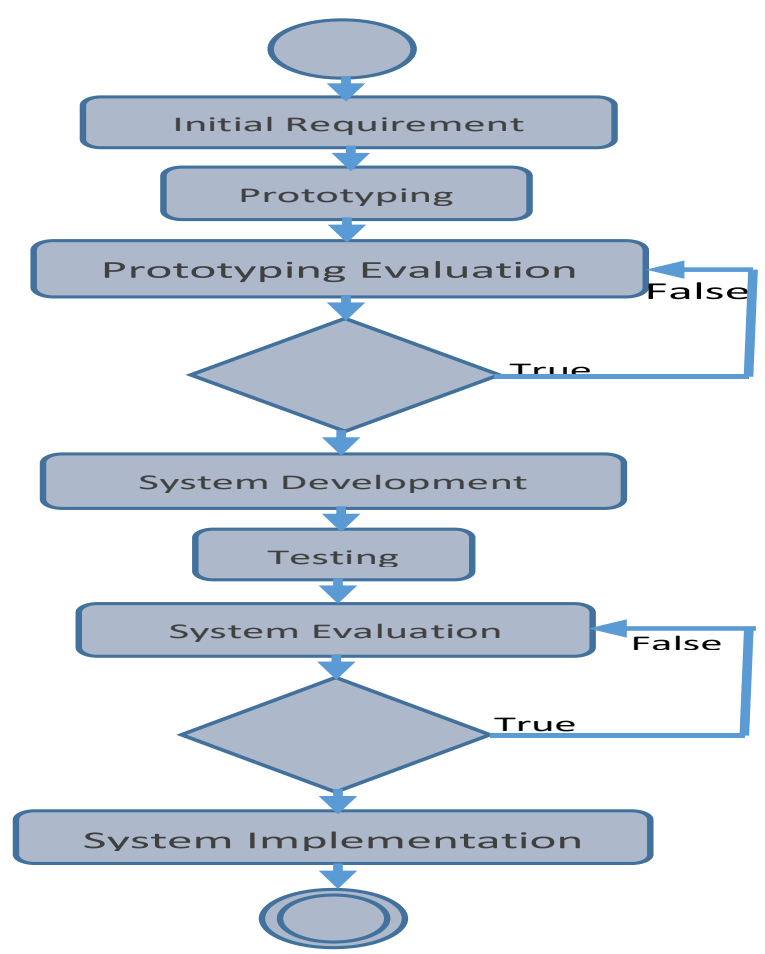

Fig 1:- Method of Prototyping

\section{RESULTS}

The system design is created using UML, it can be seen use case in Fig. 2 The interface generated in this study is divided into two, ie on the front end (for user) and back end (for administrator). Both are made with website platform using PHP programming language with MySQL database. The user interface that has been generated can be seen in the Fig. 3 and Fig. 4.

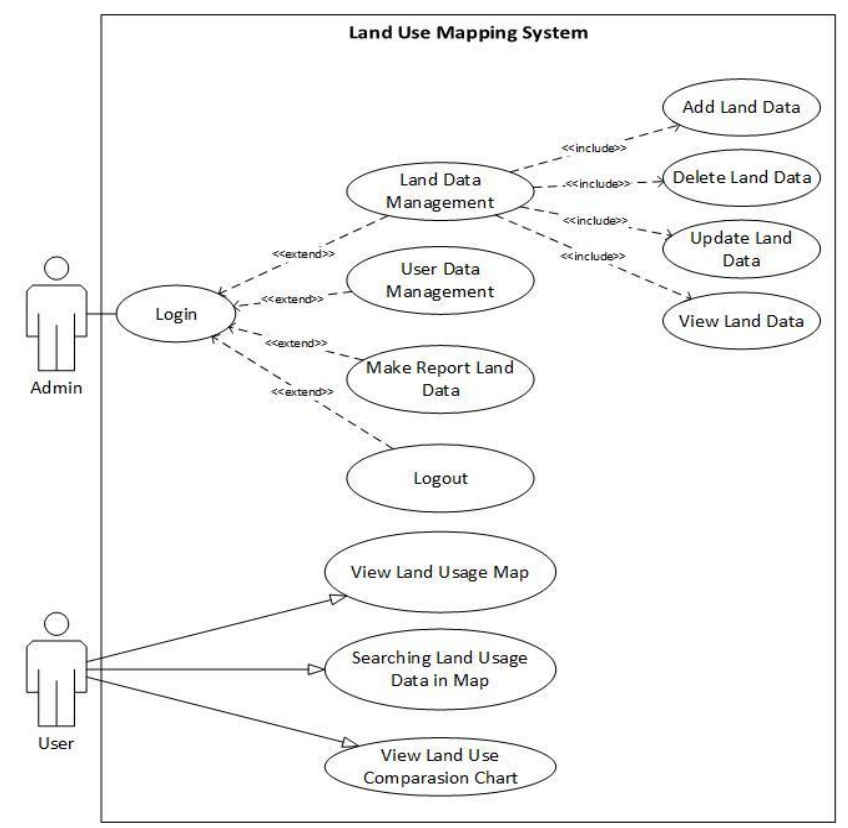

Fig 2:- Usecase Diagram 


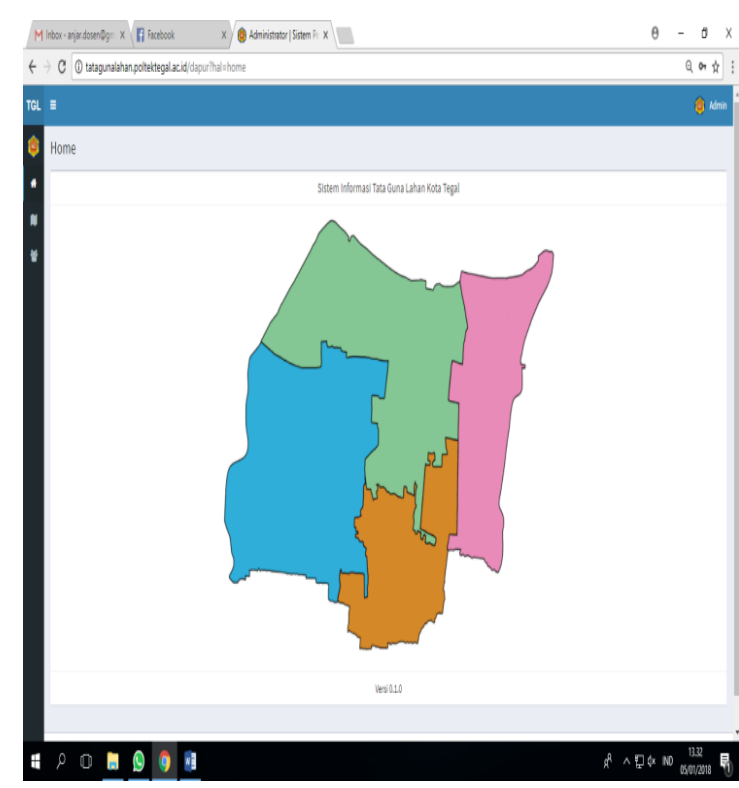

Fig 3:- Main Menu Administration

\section{Discussion}

This research uses prototyping method in system development, while the explanation of the method is as follows:

- Initial Requirement. This stage is an early stage in a study, where in this stage is done a problem identification, data collection and data analysis.

$>$ Problem Identification. At this stage identified the problem of what is the main problem so that the problem is made a core foothold of this research.

$>$ Data collection. After the identification phase of the problem has been completed, the stages of data collection with several methods, whether in the form of literature study, observation or interview with related parties.

Analysis This stage is done to analyze the collected data for further elaborated according to the need in this research, ie data needed to produce mapping land use website. Besides, in this stage is also determined what software and hardware used based on the results of data analysis.

- Building Prototype (Prototyping). This stage is a stage to produce software design that can be understood by the software engineer based on the results of the analysis that has been completed. In this case, a design is made using UML to describe the system workflow and also design UI (User Interface) and UX (User Experience) to describe the look and functional of the designed system.

- Prototyping Evaluation. The prototype evaluation is performed to re-check the prototype that has been made either UML, UI or UX design before submitted to software engineer, if the result of this evaluation there is no mistake / mistake then it can be continued to the next stage, but if there is mistake then it must be returned to the previous stage.

- System encoding (System Development). This stage is to translate the prototype evaluation results into the programming codes. In this research, programming language used is PHP with My SQL as database.

- Testing. After the encoding phase of the system has been completed, the next step is to test the system using black box testing. Black box testing is a software testing method that tests application functionality regardless of internal structure or how it works. This testing method can be applied virtually to any level of software testing: unit, integration, system and acceptance [13].

- System Evaluation. System evaluation is done to ascertain whether a system that has been developed and tested has really been in accordance with the needs and has become a solution of existing problems or not.

- Implementation System. This is the last stage in the prototyping method, after the system evaluation phase has been completed, then the next stage is to do web hosting system to be accessible wherever and whenever connected to the internet. Besides, in this phase will also be tested the security of existing systems and conducted training for web management for administrators.

\section{CONCLUSION}

Based on the results of research, it can be concluded as follows:

- Prototyping method can accelerate the development of mapping land use website

- Prototyping methods can result in the development of mapping land use website that suits the needs and wants of the client

- Website land use can be used as media information online about land use in certain areas or areas.

\section{ACKNOWLEDGMENT}

Acknowledgments specially to Indonesian Department of Transportation which has been pleased to provide partial collection of data and also to all parties who have assisted and provided support for the implementation of this research.

\section{REFERENCES}

[1]. Amler B, Etke D, Eger H, Ehrich C, Kohler A, Kutter A, von Lossau A, Mu«ller U, Seidemann S, Steurer R, Zimmermann W. 1999. Land Use Planning: Methods, Strategies and Tools. Deutsche Gesellschaft für Technische Zusammenarbeit (GTZ) GmbH. Eschborn, Germany.

[2]. Smith MF Software Prototyping: Adoption, Practice and Management. McGraw-Hill, London (1991).

[3]. Sabale \& Dani. Comparative Study of Prototype Model For Software Engineering With System Development Life Cycle. IOSR Journal of Engineering (IOSRJEN). ISSN: 2250-3021 Volume 2, Issue 7(July 2012), PP 21-24.

[4]. Thanapura, Pravara, et all. 2006. Mapping Urban Land Cover Using QuickBird NDVI and GIS Spatial Modeling for Runoff Coefficient Determination. Photogrammetric Engineering \& Remote Sensing Vol. 73, No. 1, January 2007, pp. 057-065.

[5]. Gao, Sheng et all. 2008. Online GIS services for mapping and sharing disease information. International Journal of Health Geographics 2008, 7:8 doi:10.1186/1476-072X-78.

[6]. Chang, Aileen Y et all. 2009. Combining Google Earth and GIS mapping technologies in a dengue surveillance 
system for developing countries. International Journal of Health Geographics 2009, 8:49.

[7]. Mas, J.F. 2004. Mapping land use/cover in a tropical coastal area using satellite sensor data, GIS and artificial neural networks. Estuarine, Coastal and Shelf Science 59 (2004) 219-230.

[8]. Brewer, Cynthia. A. 2006. Basic Mapping Principles for Visualizing Cancer Data Using Geographic Information Systems (GIS). American Journal of Preventive Medicine. Published by Elsevier Inc. 0749-3797/06/.

[9]. O'Brien, James. A., 2005. Introduction to Information Systems.12th Edition. New York: McGraw-Hill.

[10]. Britton, Carol; Jill Doake (2001). Object-Oriented Systems Development. McGraw-Hill. pp. 28-29, 269. ISBN 0-07-709544-8.

[11]. O'Brien \& Marakas. 2010. Management Information System: Managing Informastion Technology In The Bussiness Enterprise. 15th Ed. New York: McGraw-Hill

[12]. Walker, JR Orville; et al. (2003). Marketing Strategy: A Decision-Focused Approach. (4th ed). Mc GrawHill, New York.

[13]. [13] Jerry Gao; H.-S. J. Tsao; Ye Wu (2003). Testing and Quality Assurance for Component-based Software. Artech House.pp. 170-. ISBN 978-1-58053-735-3. 